\title{
Measurement of hydroxyproline in collagen with three different methods
}

\author{
BING QIU $^{1 *}$, FENGXIANG WEI $^{2 *}$, XIUZHI SUN ${ }^{1}$, XI WANG $^{3}$, BINHONG DUAN $^{4}$, CHUNLIN SHI $^{1}$, \\ JIANYING ZHANG ${ }^{1}$, JIYE ZHANG ${ }^{1}$, WENLIANG QIU ${ }^{1}$ and WENLING MU ${ }^{1}$ \\ ${ }^{1}$ Department of Gastroenterology, Heilongjiang Provincial Hospital, Harbin, Heilongjiang 150036; \\ ${ }^{2}$ Genetics Laboratory Shenzhen Longgang District Maternity and Child Healthcare Hospital, Shenzhen, Guangdong 518124; \\ ${ }^{3}$ Department of Gastroenterology, The First Affiliated Hospital of Harbin Medical University, Harbin, Heilongjiang 150001; \\ ${ }^{4}$ Department of Endocrinology, Heilongjiang Provincial Hospital, Harbin, Heilongjiang 150036, P.R. China
}

Received August 3, 2013; Accepted March 31, 2014

DOI: $10.3892 / \mathrm{mmr} .2014 .2267$

\begin{abstract}
Determination of the 4-hydroxy-L-proline (hydroxyproline) concentration may provide useful information for the diagnosis and prognosis of diseases caused by disorders of collagen metabolism. The objective of the present study was to apply liquid chromatography-mass spectrometry (LC-MS) to assess the hydroxyproline concentration. The hydroxyproline concentration in lung and liver tissues measured by LC-MS was compared with values obtained by a colorimetric method, as well as a fluorescence method using high-performance liquid chromatography (HPLC) from previous studies by our group. The determination of the hydroxyproline concentration by LC-MS was improved as compared with that using the colorimetric and HPLC methods, due to its simplicity, high sensitivity (pg level) and short separation time. These results suggested that utilizing the LC-MS method for measuring the hydroxyproline concentration would be advantageous for the diagnosis of diseases associated with abnormalities of collagen metabolism.
\end{abstract}

\section{Introduction}

4-hydroxy-L-proline (hydroxyproline) is a non-proteinogenic amino acid, that has a molecular weight of $131.13 \mathrm{~g} / \mathrm{mol}$ and is synthesized by post-translational hydroxylation of proline during collagen biosynthesis (Fig. 1). Investigations of physiological and pathological collagen metabolism most commonly utilize measurements of hydroxyproline in the plasma, urine and body tissue. Therefore, determination of hydroxyproline

Correspondence to: Dr Bing Qiu, Heilongjiang Provincial Hospital, 82 Zhongshan Road, Harbin, Heilongjiang 150036, P.R. China E-mail: bingqiu07@163.com

*Contributed equally

Key words: hydroxyproline, liquid chromatography-mass spectrometry, high-performance liquid chromatography, fluorescence provides useful information for the diagnosis and prognosis of diseases caused by disorders of the collagen metabolism (1). Such conditions include hyperthyroidism, hyperparathyroidism, acromegaly, Paget's disease, osteomalacia, rickets, Marfan syndrome, osteogenesis imperfecta, sclerodactyly, dermatomyositis and Cushing syndrome (2).

Fibrosis that occurs in the liver, lungs, kidneys, skin and other organs has the capacity to develop into chronic hepatitis, liver sclerosis, liver cancer, pulmonary fibrosis and glomerulonephritis (3). Therefore, preventing the development and reducing the severity of fibrosis in patients is highly important. Hydroxyproline acts as an important diagnostic indicator of the severity of fibrosis.

The measurement of hydroxyproline in plasma, urine and body tissue is possible by colorimetric methods, high-performance liquid chromatography (HPLC) and flow injection analyses (4-6). However, these methods require large sample volumes, due to their low sensitivity. In addition, HPLC requires a long separation time for each sample. In recent years, liquid chromatography-mass spectrometry (LC-MS) has been emerging as advantageous for its high sensitivity and short separation time. LC-MS has been utilized to measure low concentrations of drugs in serum and urine with contaminated substances (7-9). The present study aimed to apply the novel LC-MS method to the measurement of hydroxyproline. As an indicator of fibrosis, hydroxyproline in the liver and lung of a rat model of fibrosis was measured by LC-MS, and compared with previous results obtained by HPLC and colorimetric methods.

\section{Materials and methods}

Ethics statement. The study protocol was approved by the Ethics Committee of Harbin Medical University (Harbin, China). A standard procedure for obtaining written informed consent was included in the protocol, and was approved by the Ethics Committee of Harbin Medical University.

Reagents. Dimethylnitrosamine (DMN) and hydroxyproline were obtained from Nacalai Tesque Inc. (Kyoto, Japan). Nembutal was purchased from Dai-Nihon Pharmaceuticals 
Inc. (Osaka, Japan) and bleomycin was obtained from Nihon Kayaku Inc. (Tokyo, Japan). All other chemicals were of reagent grade.

Preparation of a model of pulmonary and liver fibrosis in rats. A model of pulmonary fibrosis was created in five-week-old Wistar rats by injection of bleomycin (BLM, $0.30 \mathrm{U} / 100 \mathrm{~g}$, i.p.) in the trachea under nembutal $(50 \mathrm{mg} / \mathrm{kg})$ anesthesia. Healthy rats were injected with $0.9 \%$ saline (control).

A model of liver fibrosis was created in seven-week-old Wistar rats by a single injection of DMN (40 mg/kg, i.p.). Normal healthy rats were the controls and were injected with $0.9 \%$ saline (control). The preparation of the pulmonary liver fibrosis model and of the collection tissue were based on the methods described in the previous studies $(10,11)$.

Measurement of hydroxyproline in a rat model of pulmonary fibrosis by a colorimetric method. The left lung was removed, weighed $(\sim 0.3 \mathrm{~g})$ and homogenized in $5 \%$ trichloroacetic acid solution (x10 volume) using a cell homogenizer (Eilard, Berlin, Germany) at $8,000 \times \mathrm{g}\left(4^{\circ} \mathrm{C}\right)$ for $2 \mathrm{~min}$ in an ice bath. Cells were centrifuged $\left(2,500 \mathrm{x} \mathrm{g}, 4^{\circ} \mathrm{C}\right)$ for $20 \mathrm{~min}$ and the supernatant washed twice with distilled water. Then, $6 \mathrm{~N} \mathrm{HCl}$ was added at $110^{\circ} \mathrm{C}$ completely at the beginning and reacted for $16 \mathrm{~h}$. Following completion of the reaction, toluene $(3 \mathrm{ml})$ was added and the mixture was agitated for $20 \mathrm{~min}$. Following centrifugation $\left(3,000 \mathrm{x} \mathrm{g}, 20^{\circ} \mathrm{C}\right)$ for $10 \mathrm{~min}$, the organic layer was collected and $p$-dimethylaminobenzaldehyde added. Hydroxyproline in the sample was detected using a Multiplate Spectrometer (Ultramark; Bio-Rad, Hercules, CA, USA) at $560 \mathrm{~nm}$.

Measurement of hydroxyproline in the liver by HPLC. The left lung was removed, weighed $(\sim 0.3 \mathrm{~g})$ and homogenized in $5 \mathrm{ml}$ ethanol using a cell homogenizer (Eilard) at $8,000 \times \mathrm{g}\left(4^{\circ} \mathrm{C}\right)$ for $2 \mathrm{~min}$ in an ice bath. The homogenate was centrifuged $\left(2,500 \mathrm{x} \mathrm{g}, 4^{\circ} \mathrm{C}\right)$ for $20 \mathrm{~min}$ and the supernatant collected. The liquid $(1 \mathrm{ml})$ was obtained and heated for $8 \mathrm{~h}$ at $60^{\circ} \mathrm{C}$ until dry. Following dissolving the residue in $40 \mu \mathrm{l}$ ethanol and $80 \mu \mathrm{l}$ borate buffer (0.1 M, pH 8), $40 \mu$ l 4-fluoro-7-nitrobenzofurazan (100 $\mathrm{mM}$ ) was added as a fluorescence reagent. The reaction was allowed to continue at room temperature for $15 \mathrm{~h}$ in the dark. Then, $840 \mu \mathrm{l}$ of hydrochloric acid $(6 \mathrm{~mol} / \mathrm{l})$ was added to terminate the reaction. Following centrifugation $(2,500 \mathrm{x} \mathrm{g}$, $20^{\circ} \mathrm{C}$ ) for $20 \mathrm{~min}$, the supernatant was removed for HPLC analysis.

A Hitachi L6000 HPLC system (Hitachi High Technologies America, Inc., Schaumburg, IL, USA) was used. Detection was performed with a Hitachi L7480 fluorescence spectrometer (Hitachi High-Technologies Corporation, Tokyo, Japan; excitation at $475 \mathrm{~nm}$, emission at $530 \mathrm{~nm}$ ). The column (Hitachi High-Technologies Corporation) was a YMC Pack ODS-AQ (150x6.0 mm ID) at room temperature. The mobile phase was acetonitrile: water (35:65-50:50 gradient over $15 \mathrm{~min})$ and the flow rate was $1 \mathrm{ml} / \mathrm{min}$.

Measurement of hydroxyproline in pulmonary and liver organization by $L C$-MS. The left lung was removed, weighed $(\sim 0.3 \mathrm{~g})$ and homogenized in $5 \%$ trichloroacetic acid solution (x10 volume) using a cell homogenizer (Eilard) at 8,000 x g

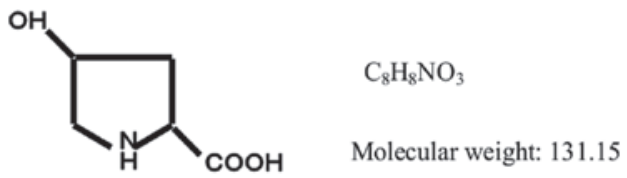

Figure 1. Structural formula of hydroxyproline.

$\left(4^{\circ} \mathrm{C}\right)$ for $2 \mathrm{~min}$ in an ice bath. Cells were centrifuged $\left(2,500 \times \mathrm{g}, 4^{\circ} \mathrm{C}\right)$ for $20 \mathrm{~min}$. The supernatant was washed twice with distilled water. Then, $6 \mathrm{~N} \mathrm{HCl}$ was added at $110^{\circ} \mathrm{C}$ for $16 \mathrm{~h}$ and the samples were prepared for measurement. The liver was removed, weighed $(\sim 0.3 \mathrm{~g})$ and homogenized in $5 \mathrm{ml}$ ethanol using a cell homogenizer (Eilard) at $8,000 \times \mathrm{g}\left(4^{\circ} \mathrm{C}\right)$ for $2 \mathrm{~min}$ in an ice bath. The homogenate was centrifuged $\left(2,500 \mathrm{x} \mathrm{g}, 4^{\circ} \mathrm{C}\right)$ for $20 \mathrm{~min}$, the supernatant collected and the samples prepared for measurement.

The concentration of hydroxyproline was determined following an LC-MS method using a LC-MS2020 system (Shimadzu Corp., Kyoto, Japan). With respect to LC, the mobile phase was $5 \% \mathrm{CH}_{3} \mathrm{CN}-10 \mathrm{mM} \mathrm{CH}_{3} \mathrm{COONH}_{4}$. The column was Shin-pack VP-ODS (150x2 mm diameter). The flow rate was $0.2 \mathrm{ml} / \mathrm{min}$. With regard to $\mathrm{MS}$, atmospheric chemical ionization (APCI) was employed. Positive ion detection was also used. The probe electron voltage was $4.5 \mathrm{kV}$ and the probe current was $4.2 \mu \mathrm{A}$. The APCI probe temperature was $250^{\circ} \mathrm{C}$ and the curved desolvation line (CDL) electron voltage was $-30.0 \mathrm{~V}$. The $\mathrm{CDL}$ temperature was $250^{\circ} \mathrm{C}$ and block temperature $20^{\circ} \mathrm{C}$. The bias voltage for Q-arrays 1,2 and 3 were 5.0, 25.0 and $35.0 \mathrm{~V}$, respectively. The Q-array RF electron voltage was $150.0 \mathrm{~V}$.

Statistical analysis. The differences between groups were examined by one-way analysis of variance. If a significant difference was noted, the difference between the groups was examined by the Bonferroni method. Correlations were examined using a two-sided t-test. $\mathrm{P}<0.05$ was considered to indicate a statistically significant difference.

\section{Results}

Measurement of the hydroxyproline concentration by LC-MS MS chromatogram of hydroxyproline. The mass spectrum of hydroxyproline is shown in Fig. 2. MS of the hydroxyproline standard $(80 \mathrm{pg} / \mathrm{ml})$ resulted in fragment peaks with a molecular mass of 173.0 (molecular ion + acetic acid-water) generated from addition to acetic acid ammonium for increasing the number of ionic molecules (molecular quantity, 131.15) and ionic strength.

LC-MS chromatogram of hydroxyproline. The LC conditions were as follows: Mobile phase, $5 \% \mathrm{CH}_{3} \mathrm{CN}-10 \mathrm{mM}$ $\mathrm{CH}_{3} \mathrm{COONH}_{4}$; column, Shin-pack VP-ODS (150x2 mm diameter); flow rate, $0.2 \mathrm{ml} / \mathrm{min}$ and ultraviolet (UV) detection at $230 \mathrm{~nm}$. MS was performed using the APCI ionization method and the ion detection was positive.

The LC-MS-selected ion monitoring (SIM) chromatogram of hydroxyproline $(m / z, 173.0)$ is presented in Fig 3. As observed for the hydroxyproline standard, a peak was observed at $1 \mathrm{ng} / \mathrm{ml}$ at a retention time of $2.213 \mathrm{~min}$. A sharp peak was also observed at $50 \mathrm{ng} / \mathrm{ml}$. At $1 \mu \mathrm{g} / \mathrm{ml}$, which was $1,000 \mathrm{x}$ the 


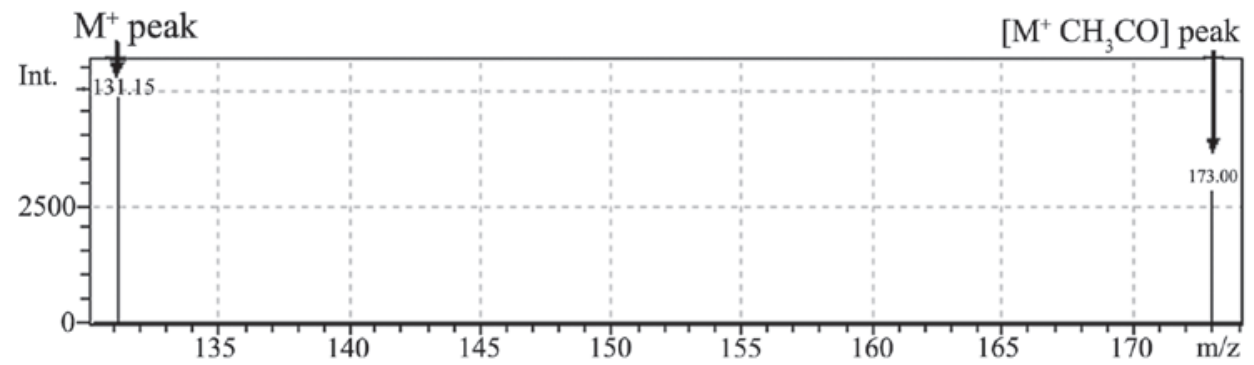

Figure 2. Mass spectrum of hydroxyproline.
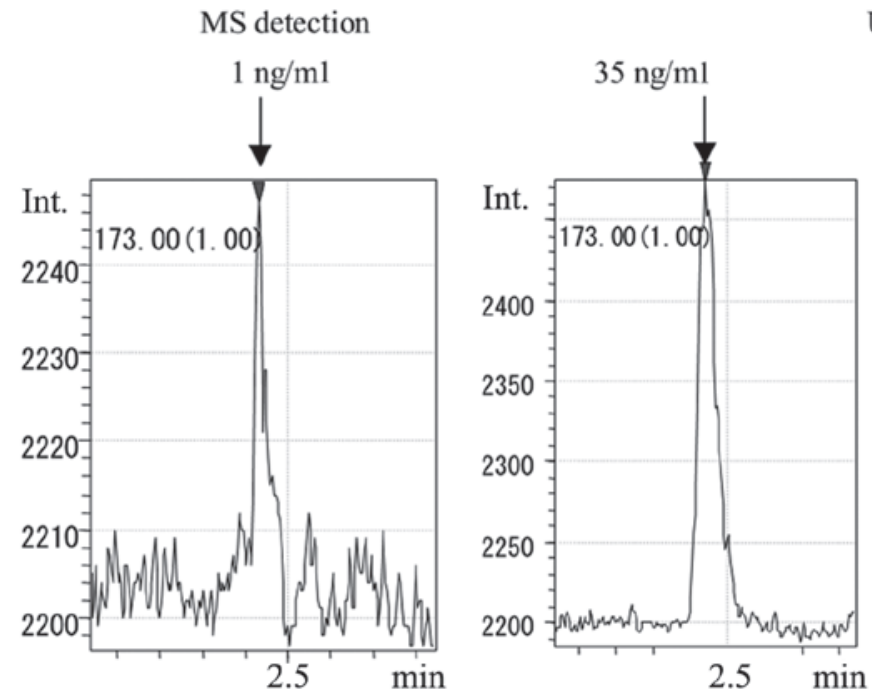

UV detection

$1 \mu \mathrm{g} / \mathrm{ml}$

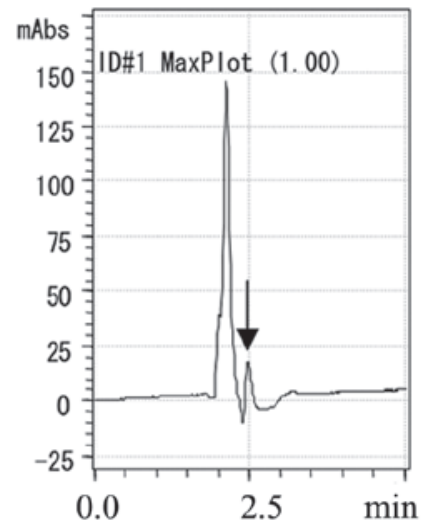

Figure 3. LC-MS-SIM chromatogram of hydroxyproline. LC-MS, liquid chromatography-mass spectrometry; SIM, selected ion monitoring; UV, ultraviolet; Int., intensity; mAbs, maximum absorbance.
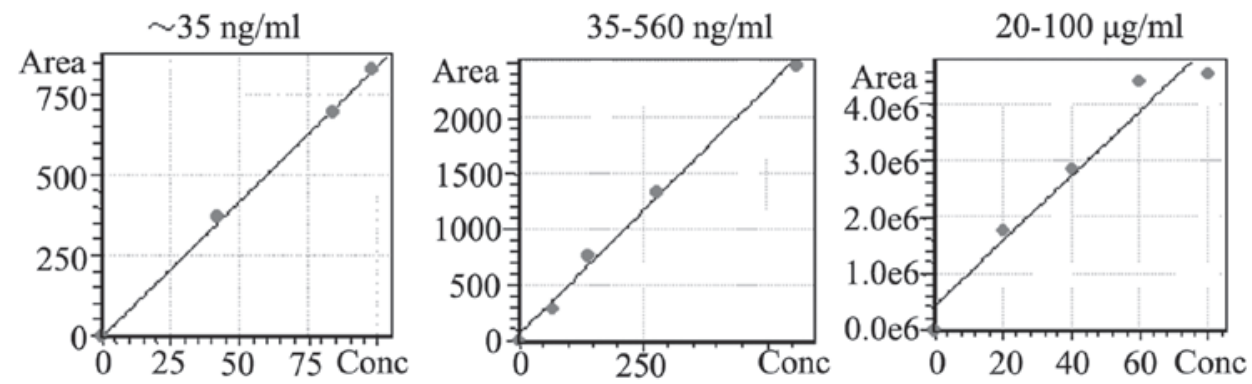

Figure 4. Standard LC-MS-SIM curve of hydroxyproline $(m / z, 173.0)$. LC-MS, liquid chromatography-mass spectrometry; SIM, selected ion monitoring; Conc, concentration.

standard concentration, a small peak was noted in the LC-UV spectrum $(230 \mathrm{~nm})$.

Sensitivity of LC-MS detection to hydroxyproline. The LC-MS-SIM standard curve of hydroxyproline $(\mathrm{m} / \mathrm{z}, 173.0$; molecular ion + acetic acid-water) is shown in Fig. 4. Using the peak area method for the standard curve, hydroxyproline exhibited a sharp peak at $35 \mathrm{ng} / \mathrm{ml}$ (Fig. 3). However, at concentrations $<35 \mathrm{ng} / \mathrm{ml}$, a correlation among the peak areas was not observed. From 35-560 ng/ml, a correlation among the peak areas was observed and the standard curve was a straight line. At 60 and $80 \mu \mathrm{g} / \mathrm{ml}$, the peak areas were almost identical. A correlation among the peak areas was not observed at concentrations $>60 \mu \mathrm{g} / \mathrm{ml}$.
LC-MS chromatogram and MS spectrum of hydroxyproline in a model of pulmonary and liver fibrosis in rats. Fig. 5 shows the LC-MS chromatogram and MS spectrum with SIM detection of hydroxyproline $(\mathrm{m} / \mathrm{z}, 173.0$; molecular ion + acetic acid-water) in a pulmonary model of fibrosis in rats. In the LC-MS chromatogram of the lung, similar to that of the hydroxyproline standard, a distinct peak at $\mathrm{m} / \mathrm{z} 173.0$ was observed at a retention time of 2,213 min. Hydroxyproline was identified at $\mathrm{m} / \mathrm{z} 131.15$ in the mass spectrum.

Fig. 6 illustrates the LC-MS chromatogram and MS spectrum with SIM detection of hydroxyproline $(\mathrm{m} / \mathrm{z}$ 173.0; molecular ion + acetic acid-water) in the fibrotic liver tissue of rats. As observed for the hydroxyproline standard, a peak was 

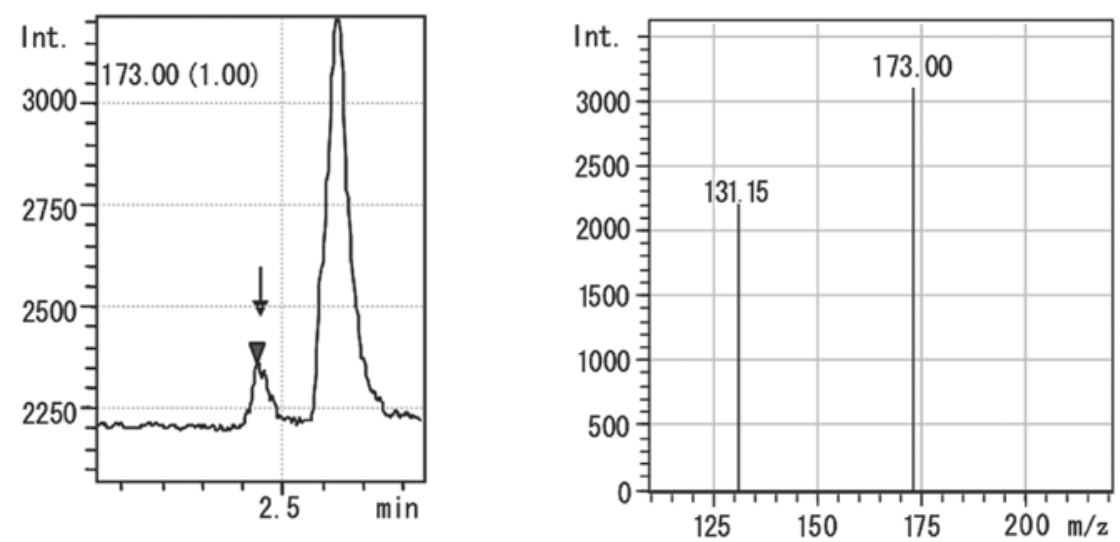

Figure 5. LC-MS chromatogram and MS spectrum of hydroxyproline in a model of fibrosis in rats. LC-MS, liquid chromatography-mass spectrometry; Int., intensity.
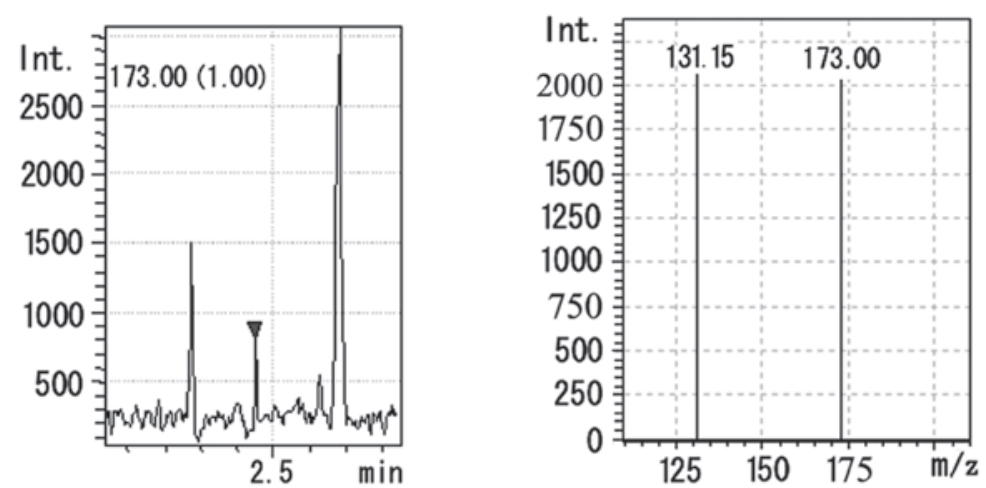

Figure 6. LC-MS chromatogram and MS spectrum of hydroxyproline in the fibrotic livers of rats. LC-MS, liquid chromatography-mass spectrometry; Int., intensity.

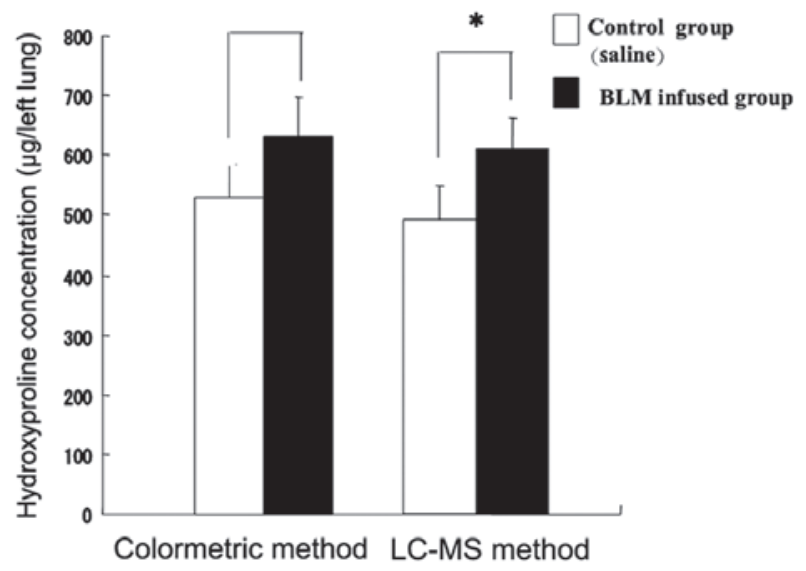

Figure 7. Hydroxyproline concentration in lung tissue of rats assessed by colorimetric and LC-MS methods. "Significant difference from the control groups. LC-MS, liquid chromatography-mass spectrometry; BLM, bleomycin. ${ }^{*} \mathrm{P}<0.05$, compared with the control group.

noted at a retention time of $2.213 \mathrm{~min}$ in the LC-MS chromatogram and MS spectrum.

Hydroxyproline concentration in lung tissue (colorimetric and LC-MS methods). Colorimetric and LC-MS methods employed for the determination of the hydroxyproline concentration in rat lung tissue are compared in Fig. 7. Each column represents the mean \pm standard deviation of nine experiments. According to the colorimetric method, the hydroxyproline concentration in rat lung tissue in the BLM-infused group (652.3 $\pm 70.0 \mu \mathrm{g} / \mathrm{left}$ lung) was significantly higher compared with that in the control group (547.1 $\pm 52.3 \mu \mathrm{g} /$ left lung; $\mathrm{P}<0.05)$. According to the LC-MS method, the BLM-infused group $(610.9 \pm 50.3 \mu \mathrm{g} / \mathrm{left}$ lung) had a significantly higher value compared with the control group $(493.3 \pm 53.5 \mu \mathrm{g} /$ left lung; $\mathrm{P}<0.05)$. However, the hydroxyproline concentration in rat lung tissue measured by the LC-MS method had a lower value compared with that measured by the colorimetric method.

The hydroxyproline concentrations in rat lung tissue measured by colorimetric and LC-MS methods are compared in Fig. 8. A correlation between the colorimetric and LC-MS methods for the determination of the hydroxyproline concentration in the lung tissue of the control group was identified $(r=0.972)$. Similarly, a correlation between the colorimetric and LC-MS methods for the determination of the hydroxyproline concentration in the lung tissue of the BLM-infused group was identified $(\mathrm{r}=0.918)$.

Hydroxyproline concentration in rat liver tissue by fluorescence labeling and LC-MS methods. The assessment of the hydroxyproline concentration in rat liver tissue by fluorescence labeling and LC-MS methods is illustrated in Fig. 9. According to the fluorescence labeling method, the hydroxyproline 


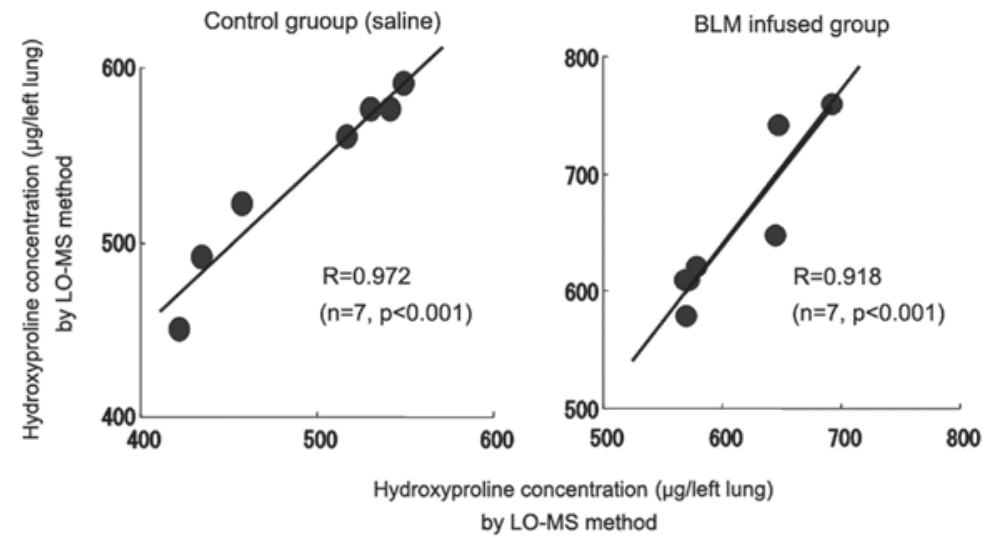

Figure 8. Correlation of colormetric and LC-MS methods for the measurement of hydroxyproline. LC-MS, liquid chromatography-mass spectrometry; BLM, bleomycin.

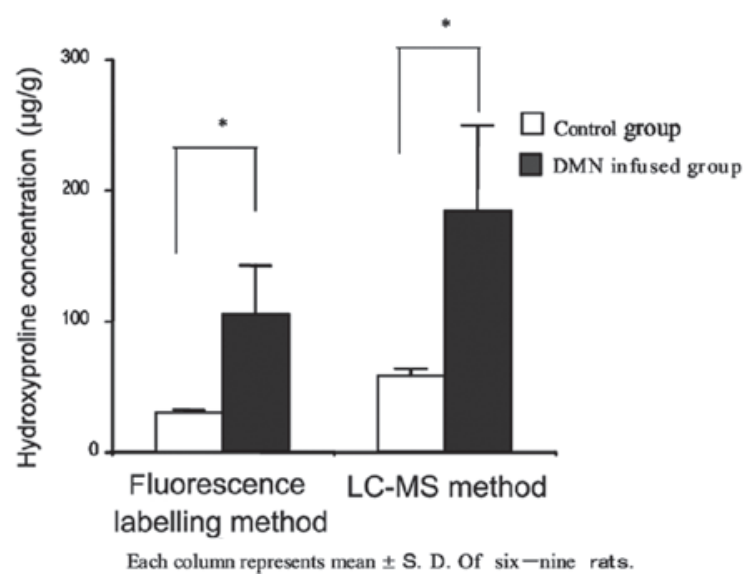

Figure 9. Assessment of hydroxyproline concentration in rat liver tissue by fluorescence labeling and LC-MS methods. LC-MS, liquid chromatography-mass spectrometry; DMN, dimethylnitrosamine; SD, standard deviation. ${ }^{*} \mathrm{P}<0.05$, compared with the control group.

concentration in rat liver tissue of the DMN-infused group $(105.4 \pm 36.5 \mu \mathrm{g} / \mathrm{g})$ was significantly higher compared with that in the control group $(30.3 \pm 2.7 \mu \mathrm{g} / \mathrm{g} ; \mathrm{P}<0.05)$. Also according to LC-MS analysis, the DMN-infused group $(190.4 \pm 70.3 \mu \mathrm{g} / \mathrm{g})$ demonstrated a significantly higher value compared with the control group $(62.4 \pm 6.8 \mu \mathrm{g} / \mathrm{g} ; \mathrm{P}<0.05)$. However, the hydroxyproline concentration in rat liver tissue measured by LC-MS was higher compared with that measured by the fluorescence labeling method.

The hydroxyproline concentration in rat liver tissue assessed by fluorescence labeling and LC-MS methods are correlated in Fig. 10. The hydroxyproline concentration in the liver tissue of the control group assessed using fluorescence labeling correlated with that obtained using the LC-MS method ( $r=0.957)$. Also, the hydroxyproline concentration in the liver tissue of the DMN-infused group obtained by the fluorescence labeling method correlated with that obtained using the LC-MS method ( $\mathrm{r}=0.981)$.

\section{Discussion}

Hydroxyproline is a type of amino acid found in albumen. The proline residue in the protein is hydroxylated by
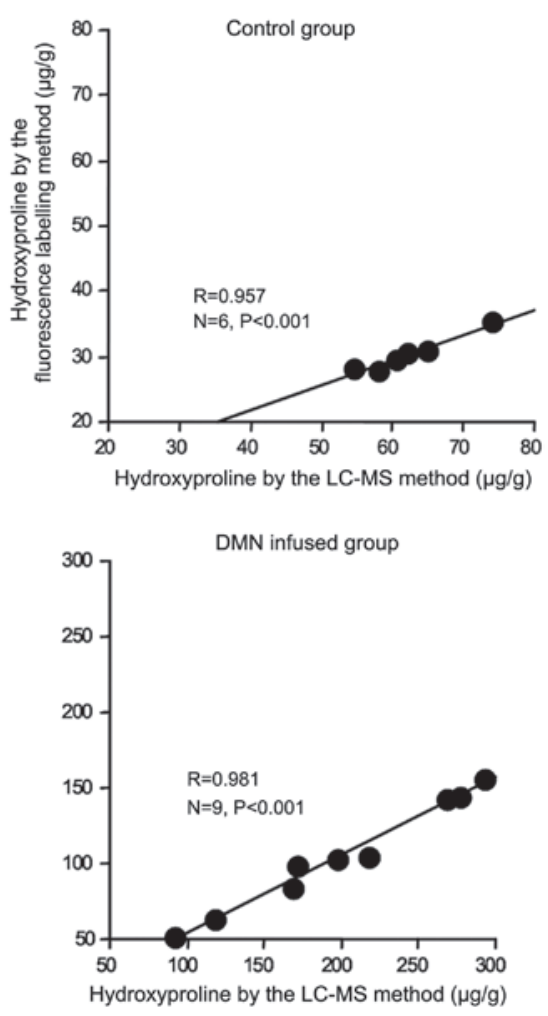

Figure 10. Hydroxyproline concentration in rat liver tissue by fluorescence labeling and LC-MS methods. LC-MS, liquid chromatography-mass spectrometry; DMN, dimethylnitrosamine.

4-monooxgenase to generate 4-hydroxy-2-oxoglutal acid, which is converted to alanine and glycine via 4-glutamic acid in the human body. In each internal organ of the body, inflammation and fibrosis may give rise to the accumulation of components of the extracellular matrix (ECM) (12). However, under pathological conditions, additional fibrosis may occur in the liver, lungs and kidneys $(13,14)$. Chronic hepatitis and liver sclerosis are associated with fibrosis and also have a close correlation with liver cancer (15).

In the lungs, the severity of fibrosis is dependent on the type of pneumonia (16). Usually, pulmonary fibrosis accompanies interstitial pneumonia (17). Fibrosis in internal organs is caused by proliferation of ECM components deposited 
by myofibroblasts. Understanding the development of fibrosis involves the examination of collagen concentration. The hydroxyproline concentration is associated with collagen as an indicator of the severity of fibrosis (18-20). Hydroxyproline is important as an index of the disease caused by collagen proliferation (as in fibrosis) and metabolism malfunction.

In recent years, LC-MS has been demonstrated to be a highly sensitive detection method $(7,8,21)$. LC-MS comprises an LC and MS component, and the interface that connects them. The LC part is identical to conventional HPLC. The sample is ionized by the interface section. Thermospray ionization produced unstable (volatile) products, so that APCI was used (which ionizes material, but not the solvent, following nebulization with solvent under atmospheric pressure). Electrospray ionization (ESI) may be used to ionize molecules of high polarity and high molecular weight, which is ideally suited to the interface component. However, in the present study, ESI was not adapted to the measurement of hydroxyproline in body specimens, as ESI was not accompanied by the thermospray in case of ionization. It was a more simple procedure to measure hydroxyproline combined with $\mathrm{Na}^{+}$by adding additional $\mathrm{Na}^{+}$to the sample.

The MS spectrum of hydroxyproline demonstrated peaks of $\mathrm{m} / \mathrm{z} 173.0$ and $131.15 \mathrm{~m} / \mathrm{z} 173.0$ was identified as the peak representing the acetic-acid salt originating from the acetic acid ammonium that was added to the mobile phase to increase ionic strength. Furthermore, due to the comparative strength of $\mathrm{m} / \mathrm{z}, 131.15$ and 173.0 being approximately identical in the MS spectrum, the ion of $m / z 173.0$ was chosen by SIM in the MS chromatogram in order to avoid the interference peak of the mobile phase.

In the MS chromatogram of the hydroxyproline standard at $1 \mathrm{ng} / \mathrm{ml}$, a peak was observed in the SIM measurement with $m / z$ 173.0. In the UV spectrum $(230 \mathrm{~nm})$ of hydroxyproline at $1 \mu \mathrm{g} / \mathrm{ml}$, which was $1,000 \mathrm{x}$ the standard concentration, a small peak was observed (measurement was performed at the same time as the LC measurement).

At concentrations $<35 \mathrm{ng} / \mathrm{ml}$, among the peak areas, no strong correlation was observed between the different methods, and it was not possible to create a standard curve. It was hypothesized that the analyte may have been affected by the peak of the mobile phase, as hydroxyproline has a comparatively low molecular weight (131.15). In addition, the peak retention time may have become unstable due to the polarity of the solvent at low concentrations (hydroxyproline concentration $<35 \mathrm{ng} / \mathrm{ml}$ ).

It was hypothesized that it may be possible to measure concentrations of substances as low as the $\mathrm{pg} / \mathrm{ml}$ level. For the peak of hydroxyproline in the MS chromatogram, the retention time was short (2.213 min). The capability of hydroxyproline to be maintained on the ODS column was weaker than originally proposed. The relative ion strength in the MS spectrum at $\mathrm{m} / \mathrm{z} 131.15$ and 173.0 was approximately identical, and accordingly, the interference peak of the mobile phase chose an ion of $m / z$ 173.0. In the LC-MS chromatogram of hydroxyproline in lung and liver tissue, a sharp peak of $\mathrm{m} / \mathrm{z} 173.0$ was observed at a retention time of $2.213 \mathrm{~min}$, just as for the hydroxyproline standard. With respect to the MS spectrum, the molecular ion peak of hydroxyproline $(\mathrm{m} / \mathrm{z} 131.15)$ was confirmed.

Measurement of the hydroxyproline concentration in lung and liver tissues by LC-MS was compared with that obtained by the colorimetric method as well as a fluorescence method using HPLC from a previous study by our group. A highly significant positive correlation was noted. However, the value of the hydroxyproline concentration in the lung obtained by the colorimetric method was higher than that obtained by LC-MS. Furthermore, the hydroxyproline concentration in the liver obtained by the fluorescence method using HPLC was lower compared with the value obtained by LC-MS (which was supposed to be a high absorbance of all components in the sample at a constant wavelength of $560 \mathrm{~nm}$ ).

In conclusion, hydroxyproline, as an indicator of fibrosis, was measured by colorimetric and HPLC methods in previous studies by our group. By comparison, the present study identified that the LC-MS method was more advantageous, characterized by its simple process, high sensitivity (pg level) and short separation time. Further investigations with larger sample sizes are warranted to confirm these results.

\section{Acknowledgements}

The authors are grateful to $\mathbf{M}$. Kusunose, M. Ono and A. Hamada (Department of Pharmacy, Kochi Medical School, Kochi, Japan) for providing several reagents used in this study, helpful suggestions and technical expertise. This work was funded by the Public Health Department of Heilongjiang Province (no. 2013365) of China.

\section{References}

1. Kitchener RL and Grunden AM: Prolidase function in proline metabolism and its medical and biotechnological applications. J Appl Microbiol 113: 233-247, 2012.

2. Myllyharju J: Prolyl 4-hydroxylases, key enzymes in the synthesis of collagens and regulation of the response to hypoxia, and their roles as treatment targets. Ann Med 40: 402-417, 2008.

3. Wick G, Grundtman C, Mayerl C, et al: The immunology of fibrosis. Annu Rev Immunol 31: 107-135, 2013.

4. Hofman K, Hall B, Cleaver H and Marshall S: High-throughput quantification of hydroxyproline for determination of collagen. Anal Biochem 417: 289-291, 2011.

5. McAnulty RJ: Methods for measuring hydroxyproline and estimating in vivo rates of collagen synthesis and degradation. Methods Mol Med 117: 189-207, 2005.

6. McCooeye M and Mester Z: Comparison of flow injection analysis electrospray mass spectrometry and tandem mass spectrometry and electrospray high-field asymmetric waveform ion mobility mass spectrometry and tandem mass spectrometry for the determination of underivatized amino acids. Rapid Commun Mass Spectrom 20: 1801-1808, 2006.

7. Jemal M and Xia YQ: LC-MS Development strategies for quantitative bioanalysis. Curr Drug Metab 7: 491-502, 2006.

8. Chen G and Pramanik BN: LC-MS for protein characterization: current capabilities and future trends. Expert Rev Proteomics 5: 435-444, 2008.

9. Becker S, Kortz L, Helmschrodt C, et al: LC-MS-based metabolomics in the clinical laboratory. J Chromatogr B Analyt Technol Biomed Life Sci 883-884: 68-75, 2012.

10. Cui T, Kusunose M, Hamada A, et al: Relationship between the eosinophilia of bronchoalveolar lavage fluid (BALF) and the severity of pulmonary fibrosis induced by bleomycin in rats. Biol Pharm Bull 26: 959-963, 2003.

11. Kusunose M, Qiu B, Cui T, Hamada A, et al: Effect of Sho-saiko-to extract on hepatic inflammation and fibrosis in dimethylnitrosamine induced liver injury rats. Biol Pharm Bull 25: 1417-1421, 2002.

12. Maruyama K: Hydroxproline. Nihon Rinsho 62 (Suppl 12): 220-223, 2004 (In Japanese).

13. Muiznieks LD and Keeley FW: Molecular assembly and mechanical properties of the extracellular matrix: A fibrous protein perspective. Biochim Biophys Acta 1832: 866-875, 2013. 
14. Lu P, Takai K, Weaver VM and Werb Z: Extracellular matrix degradation and remodeling in development and disease. Cold Spring Harb Perspect Biol 3: a005058, 2011.

15. Pungpapong S, Kim WR and Poterucha JJ: Natural history of hepatitis B virus infection: an update for clinicians. Mayo Clin Proc 82: 967-975, 2007.

16. Strieter RM and Mehrad B: New mechanisms of pulmonary fibrosis. Chest 136: 1364-1370, 2009.

17. Swigris JJ and Brown KK: Acute interstitial pneumonia and acute exacerbations of idiopathic pulmonary fibrosis. Semin Respir Crit Care Med 27: 659-267, 2006.

18. Ono M, Miyamura M, Kyotani S, et al: Effects of Sho-saiko-to extract on liver fibrosis in relation to the changes in hydroxyproline and retinoid levels of the liver in rats. J Pharm Pharmacol 51: 1079-1084, 1999.
19. Ono M, Miyamura M, Kyotani S, et al: Effect of Sho-saiko-to extract on HGF and TGF-beta levels of intraorgans in liver-injured rats after partial hepatectomy. J Pharm Pharmacol 52: 111-118, 2000.

20. Kusunose M, Qiu B, Cui T, et al: Effect of Sho-saiko-to extract on hepatic inflammation and fibrosis in dimethylnitrosamine induced liver injury rats. Biol Pharm Bull 25: 1417-1421, 2002.

21. Holčapek M, Jirásko R and Lísa M: Recent developments in liquid chromatography-mass spectrometry and related techniques. J Chromatogr A 1259: 3-15, 2012. 